\title{
Getting the Answer Exactly Right: Dealing with Math Misconception
}

\author{
Elymar A. Pascual \\ elymarpascual@rocketmail.com \\ Department of Education, Nagcarlan, Laguna, Philippines, 4002
}

\begin{abstract}
It is generally agreed Mathematics is a complex subject that caters to the higher order thinking skill of learners and teachers as well. Twelve misconceptions in Mathematics have been established in the past decades and not every one of these misconception can be said to have subsided in the education arena, but continue to promulgate as they were not dealt with in a day-to-day classroom scenario. This study focused on investigating on one Math misconceptions, "It is always important to get the answer exactly right." Fifty-seven high school learners were asked to rate the different Math misconceptions and getting the answer exactly right revealed to have the highest mean level compared to other Math misconceptions. Participants were interviewed to share their idea why they think it is always important to get the answer exactly right and most answers appeared to be learning experiential in nature. Recommendations were given to Math teachers in focusing into the process of getting the answer rather than the end-product, though it is indeed needed to get the answer exactly right.
\end{abstract}

Keywords: misconception; Mathematics; Math problem; Math answer

\section{Introduction}

A person was in a department store, trying to buy all his needs with the $\mathrm{P} 2,000$ he had in his pocket. But he was afraid that the amount of the goods his putting in the trolley might exceed. He tried to compute the amount of goods he already had but his self concept that he's not good in math stopped him from doing so. So he just limited the goods his getting but ended up paying the cashier with a sum of a little bit more than P1,000 and was dismayed that he didn't get all the goods that he needed.

Some of us may have an experience similar to this. Having misconceptions with the things about Mathematics is prevalent that more and more studies have been made to reveal the truth and to help those having hard time dealing with the things about Math, either in learning or in teaching.

This paper focuses in dealing with the reasons of the students on why they believe it's always important to get the answer in Math problems exactly right, and in suggesting possible solution to this misconception based on the reason of the students. Respondents on a survey question were 57 high school students of Sta. Cruz, Laguna, Philippines.

\section{Conceptual Framework (Evidence Supporting the Misconception)}

Kogelman \& Warren, 1978 in their article Mind over mathematics came up with the twelve myths in Mathematics: (1) Some people have a "math mind" and some don't; (2) There is a best way to do a math problem; (3) Math is creative; (4) It is not always know-how you got the answer; (5) It is always important to get the answer exactly right; (6) It is bad to count on your fingers; (7) Men are better in man than in women; (8) Mathematicians do problem quickly in their heads; (9) There is a magic way in doing math; (10) Math requires a good memory; (11) One should stop solving a problem if can no longer continue; and (12) Math 
requires intuition, not logic. All of these misconceptions can give an impact to students that math is a hard 307 subject.

University of Alaska Fairbanks (2022) elaborated this in the article entitled "Twelve Math Myths."

- Men are better in Math then women.

Research has failed to show any difference between men and women in mathematical ability. Men are reluctant to admit they have problems so they express difficulty with math by saying, "I could do it if I tried." Women are often too ready to admit inadequacy and say, "I just can't do math."

- Math requires logic, not intuition.

Few people are aware that intuition is the cornerstone of doing math and solving problems. Mathematicians always think intuitively first. Everyone has mathematical intuition; they just have not learned to use or trust it. It is amazing how often the first idea you come up with turns out to be correct.

- Math is not creative.

Creativity is as central to mathematics as it is to art, literature, and music. The act of creation involves diametrical opposites--working intensely and relaxing, the frustration of failure and elation of discovery, satisfaction of seeing all the pieces fit together. It requires imagination, intellect, intuition, and aesthetic about the rightness of things.

- You must always know how you got the answer.

Getting the answer to a problem and knowing how the answer was derived are independent processes. If you are consistently right, then you know how to do the problem. There is no need to explain it.

- There is a best way to do Math problems.

A math problem may be solved by a variety of methods which express individuality and originalitybut there is no best way. New and interesting techniques for doing all levels of mathematics, from arithmetic to calculus, have been discovered by students. The way math is done is very individual and personal and the best method is the one which you feel most comfortable.

- It's always important to get the answer exactly right.

The ability to obtain approximate answer is often more important than getting exact answers. Feeling about the importance of the answer often are a reversion to early school years when arithmetic was taught as a feeling that you were "good" when you got the right answer and "bad" when you did not.

- It's bad to count on your fingers.

There is nothing wrong with counting on fingers as an aid to doing arithmetic. Counting on fingers actually indicates an understanding of arithmetic-more understanding than if everything were memorized.

- Mathematicians do problems quickly, in their heads.

Solving new problems or learning new material is always difficult and time consuming. The only problems mathematicians do quickly are those they have solved before. Speed is not a measure of ability. It is the result of experience and practice.

- Math requires a good memory.

Knowing math means that concepts make sense to you and rules and formulas seem natural. This kind of knowledge cannot be gained through rote memorization.

- Math is done by working intensely until the problem is solved.

Solving problems requires both resting and working intensely. Going away from a problem and later returning to it allows your mind time to assimilate ideas and develop new ones. Often, upon coming back to a problem a new insight is experienced which unlocks the solution.

- Some people have a "Math mind" and some don't.

Belief in myths about how math is done leads to a complete lack of self-confidence. But it is selfconfidence that is one of the most important determining factors in mathematical performance. We have yet to encounter anyone who could not attain his or her goals once the emotional blocks were removed.

- There is a magic key to doing Math.

There is no formula, rule, or general guideline which will suddenly unlock the mysteries of math. If there is a key to doing math, it is in overcoming anxiety about the subject and in using the same skills you use to do everything else. 
From the different misconceptions, Anderton (2019) made a survey to 1, 071 and lined up the biggest 308 misconceptions students have about Math. He emphasized that these misconceptions are the ones that are keeping students from succeeding. The next figure shows the distribution from the highest to the lowest percentage of respondents' choice of misconceptions that are hindering their success.

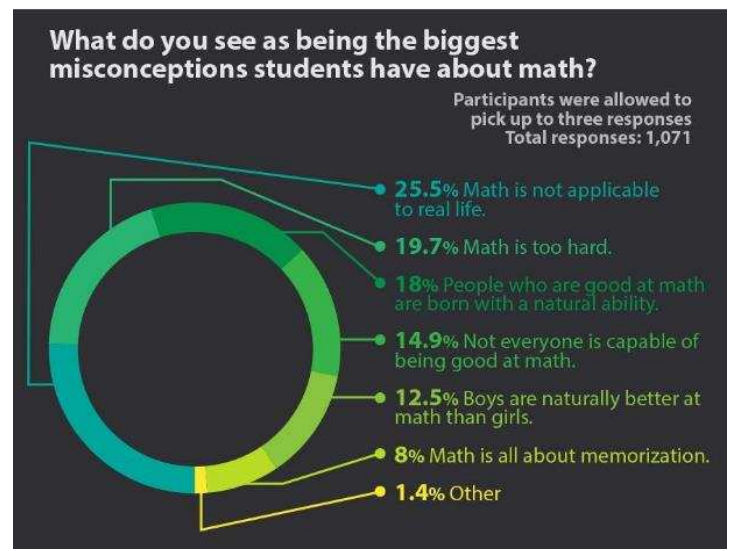

Fig. 1. The misconceptions about math that are keeping students from succeeding

The figure shows that respondents believe the leading misconception that is hindering students to succeed is "Math is not applicable to real life" (25.5\%), followed by "Math is too hard" (19.7\%), "People who are good at Math are born with a natural ability" (18\%), "Not everyone is capable of being good at Math" (14.9\%), "Boys are naturally better at Math than girls" (12.5\%), "Math is all about memorization" (8\%), and all other misconceptions obtained $1.4 \%$ choice from the respondents.

Penaso ( 2002) made a study on these myths by administering survey to the fourth year students of Central Mindanao University laboratory High School. Results showed that students believe some myths, particularly on the nature of mathematics and mathematical tasks as well as on the preconceived notions of themselves and others as doers of mathematics.

In "Myths in math.htm" we can read the following argument:

True or False: You need to memorize a lot of facts, rules and formulas to be good at math.

False: ... Memorizing procedures is not as effective as conceptually understanding concepts.

For instance, memorizing the fact $9 \times 9$ is not as important as understanding that $9 \times 9$ is groups of 9. Applying thinking skills and creative thought lead to a better understanding of math. Signs of understanding include those "Aha" moments! The most important aspect to learning math is understanding. Ask yourself after solving a math problem: are you applying a series of memorized steps/procedures, or do you really 'understand' how and why the procedure works.

This is similar in saying that knowing the exact answer in $9 \times 9$ is not more important than knowing the reason why $9 \times 9$ is equal to 81 . Thus, all of these readings agree that it is not always important to know the exact answer in Mathematics problem.

In "How Math is Different from Other Subjects" by University of Alaska Fairbanks (2022), the nature of Mathematics that produces different misconception to learners and even teachers is explained.

- Math requires different study processes. In other courses, you learn and understand the material, but you seldom have to actually APPLY IT. You have to do the problems. 
- Math is a linear learning process. What is used one day is used the next, and so forth. (In history you can learn chapter 2 and not 3 and do OK on 4 . In math, you must understand the material in chapter 1 before you go on to chapter 2.)

- Math is much like a foreign language. It must be practiced EVERY DAY, and often the VOCABULARY is unfamiliar.

- Math in the university is different from math in high school. In college, you go only two or three times a week to your class. What took a year to learn in high school is now covered in only fifteen weeks.

\section{Result, Discussion and Suggestion}

A survey was conducted to the high school students of UECS, Sta. Cruz, Laguna using the 12 myths by Kogelman \& Warren (1978). A 5-point Likert Scale method was used to reveal students beliefs and the fifth item (It is always important to get the answer exactly right.) got the highest mean $(4.26, \mathrm{SD}=1.01)$

\begin{tabular}{|c|c|c|}
\hline Misconceptions in Math & Mean & SD \\
\hline (1) Some people have a "math mind" and some don't & 3.51 & 1.09 \\
\hline (2) There is a best way to do a math problem & 4.18 & 1.10 \\
\hline (3) Math is creative & 4.11 & 0.82 \\
\hline (4) It is not always know-how you got the answer & 2.82 & 1.38 \\
\hline (5) It is always important to get the answer exactly right & 4.26 & 1.01 \\
\hline (6) It is bad to count on your fingers & 2.72 & 1.26 \\
\hline (7) Men are better in man than in women & 2.70 & 1.36 \\
\hline (8) Mathematicians do problem quickly in their heads & 3.37 & 0.99 \\
\hline (9) There is a magic way in doing math & 3.28 & 1.28 \\
\hline (10) Math requires a good memory & 3.74 & 1.16 \\
\hline (11) One should stop solving a problem if can no longer continue & 1.74 & 1.03 \\
\hline (12) Math requires intuition, not logic & 1.75 & 0.76 \\
\hline
\end{tabular}

Shortly after that, a written interview was conducted to know why they say that it is always important to get the answer exactly right. Some of their reasons were as follows:

- "It is always important to get the answer exactly right. Why? Obviously because when you didn't get it then you're wrong. Mr......... is the only teacher that gives points even if you're answer is wrong. But the other teacher don't. For example, in my English test, in English if you only miss even a punctuation, it will not be recognizable as a sentence. That's how strict it is. So it's very important to write the correct and complete answer." Participant 1

- "It is always important to get the right answer because it is supposed to be a calculation and should be specific. If you are an engineer building the tallest sky scrapper and your computations are erroneous your building and your career is in jeopardy." Participant 2

- "Since my elementary years, I was been bombarded?? That I should get the exact answer in a math problem or else, obviously I might get a wrong answer which is true indeed... I haven't seen a lecture that implies that it's ok not to get the exact answer. That's why I have a perception that I should get the exact answer which is only the answer in a problem." Participant 3

- "It's always important to know the exact answer in Math problems because there's always a formula given. Teachers give us formula for certain math problems but some are just too easy for formulas to be given. It's also important because if it's not exact you'll be wrong." Participant 4

- "For me it is always important to know the exact answer in Math problems because it can really help each of us to have a good or higher grades. For example, if we have our quiz or test then you don't know how to get the answer. It is a very big lost especially when you really want to have a high grade. So we must to know it well." Participant 5 


\section{Summary of Findings}

Other answers are almost alike with the five mentioned. This means that we can summarize the reasons as follows:

1.) Students had an experience of not having any credit for their work just because their final answer is wrong.

2.) Students associate getting inexact answer to their fear of doing wrong in the future.

3.) Students think, or someone made them think that things in this world should be perfect.

4.) Students believe that because there is a formula given, they should get the exact answer even without understanding the formula.

5.) Students want to get the exact answer because they want to have high grades.

\section{Conclusions and Recommendations}

Based on the reasons of the students on why they believe that it is always important to get the answer exactly right, the following conclusions and recommendations are formulated:

- Math teachers should always consider and give credit to the solutions of the students when checking for the answer on problem solving exams. One of the arguments that appeared in the study of Penaso (2002) is this: "I think it is not so important (well, partly important) to get the answer exactly right. Even if you did not get the final answer because you failed in some steps (say, wrong sign), as long as you follow correct procedure, it is okay."

- Math teachers should inculcate to the students that they should not fear having failure in trying. It's better to try and fail than never to have tried at all. Charles Kettering (1876-1958) said, "Teach a highly educated person that it is not a disgrace to fail and he must analyze every failure to find its cause. He must learn how to fail intelligently, for failing is one of the greatest arts in the world."

- Math teachers should be an example of not being a perfectionist but at the same time preserving the standard of Mathematics. Jean Piaget, a Swiss psychologist, once opined that a child who has a different answer from a certain problem doesn't necessarily mean that he's wrong. Instead, that's a sign that the child has a different notion about the matter. It is, at that point, that the role of the teacher in facilitating the right logical thinking should enter.

- Math teachers should emphasize to the students that there are several ways of arriving to a correct answer. Having them known this, they will always think first and consider their solution if it is appropriate or logical for a given problem.

- Math teachers should emphasize the value of learning. Marks and grades are just indications of how much they learned. This paper does not suggest that getting the exact answer is not needed. This just emphasizes that understanding the logical processes involved is always important. Getting the exact answer and high grades just follow.

\section{References}

Anderton, K. (Apr 28, 2019). The misconceptions about math that are keeping students from succeeding [infographic]. Forbes. https://www.forbes.com/sites/kevinanderton/2019/04/28/the-misconceptions-about-math-that-are-keeping-students-fromsucceeding-infographic/?sh=503d90da4dd9

Kogelman, S. \& Warren, J. (1978). Mind over mathematics. New York: McGraw-Hill.

Penaso, Anthony M. (2002). Student perceptions of Mathematics myths: Curricular and instructional implications. Central Mindanao University.

Student Learning Assistance Center (SLAC). (Summer 1999). Mind over Math. Southwest Texas State University. McGraw-Hill Book Company, pp. 30-43.

University of Alaska Fairbanks, Department of Developmental Education. Twelve Math myths. Scribbr. January 15, 2022 https://www.uaf.edu/deved/math/help-for-math-anxiety/12-math-myths/ 